\title{
Estudo das Propriedades Térmicas de Filmes Poliméricos Compostos de Speek, Derivados do Benzoimidazol e Ácido Fosfotúngstico
}

\author{
Fabrício Celso, Raquel S. Mauler \\ Instituto de Química, UFRGS
}

\author{
Ailton S. Gomes \\ Instituto de Macromoléculas Professora Eloisa Mano, UFRJ
}

Resumo: Filmes poliméricos foram desenvolvidos a partir de poli (éter éter cetona) sulfonado (SPEEK), derivados do benzoimidazol e ácido fosfotúngstico (HPW). Neste trabalho foi realizado um estudo utilizando a análise termogravimétrica com o objetivo de avaliar a estabilidade térmica e determinar as condições de temperatura a que podem ser submetidos os filmes produzidos, tendo em vista a aplicação de tais filmes como membranas em células a combustível. Os resultados obtidos mostram que a estabilidade térmica é afetada pela composição dos filmes. A maioria dos filmes se mostrou estável até $140{ }^{\circ} \mathrm{C}$.

Palavras-chave: Poli (éter éter cetona), sulfonação, benzoimidazol, ácido fosfotúngstico, termogravimetria.

\section{Thermal Properties of Speek-based Polymeric Films Containing Benzimidazole Derivatives and Fosfotungstic Acid}

\begin{abstract}
Polymeric films were developed from sulfonated poly(ether ether ketone) (SPEEK), benzimidazole derivatives and phosphotungstic acid (HPW). In this study, thermogravimetric analysis was performed with the aim of evaluating the temperature conditions to which polymeric films can be submitted. The results showed that thermal stability depended on film composition and the majority of the tested films showed to be stable up to $140{ }^{\circ} \mathrm{C}$.
\end{abstract}

Keywords: Poly (ether ether ketone), sulfonation, benzimidazole derivatives, fosfotungstic acid, thermogravimetric analysis.

\section{Introdução}

No decorrer dos anos, a sociedade moderna defronta-se cada vez mais com obstáculos, cuja superação é de fundamental importância para o futuro. Dos principais desafios a serem vencidos, apresentam-se o esgotamento dos combustíveis fósseis e a degradação do meio ambiente, que estão intimamente relacionados, uma vez que uma das principais fontes de poluição ambiental é o uso de combustíveis fósseis para geração de energia ${ }^{[1]}$.

O desenvolvimento de energias alternativas renováveis, não-poluentes e de baixo custo constitui-se, então, em um dos grandes desafios da sociedade contemporânea. A questão sobre a substituição de um modelo de geração de energia baseado no petróleo por um modelo baseado em fontes renováveis é de suma importância. Dessa forma, a descoberta e a utilização de novas alternativas de energia autosustentáveis serão determinantes da própria preservação do planeta para as futuras gerações.

De maneira análoga às energias solar, eólica e da biomassa, as células a combustível entram nesta contextualização, apropriadamente, como uma tecnologia de geração de energia a partir de fontes renováveis, uma vez que estas compreendem sistemas de geração de energia onde um combustível é convertido eletroquimicamente em energia ${ }^{[1]}$.

Dentre os diversos tipos de células a combustíveis existentes atualmente ${ }^{[2-5]}$, aquelas que utilizam membranas poliméricas como eletrólito, tem apresentado um avançado progresso na sua tecnologia, principalmente no que diz respeito ao desenvolvimento de novas membranas para essa aplicação ${ }^{[6]}$.

Membranas para células a combustível de eletrólito polimérico são produzidas geralmente a partir de polímeros perfluorados, como Nafion ${ }^{\circledR[7]}$. Entretanto, outros polímeros têm sido estudados para essa mesma finalidade, como é o caso da policetona ${ }^{[8]}$ e da polissulfona ${ }^{[9]}$. Esses polímeros estão sendo avaliados a fim de se desenvolverem membranas que apresentem menor custo e melhores propriedades do que as membranas perfluoradas, uma vez que essas últimas apresentam limitações devido à desidratação, quando utilizadas em operação acima de $100{ }^{\circ} \mathrm{C}$, e envenenamento por monóxido de carbono (CO), quando hidrogênio de alto grau de pureza não é utilizado. As membranas poliméricas obtidas a partir de um polímero comercial mesmo que sulfonado, também

Autor para correspondência: Ailton S. Gomes, Instituto de Macromoléculas Professora Eloisa Mano, UFRJ, Caixa Postal 68525, CEP: 21945-970,

Rio de Janeiro, RJ, Brasil. E-mail: asgomes@ima.ufrj.br 
não atingem um desempenho satisfatório nas mesmas condições, sendo interessante considerar outros componentes na composição das mesmas, de forma a se obter blendas ${ }^{[10]}$ ou compósitos ${ }^{[11]}$.

O poli(éter éter cetona) sulfonado (SPEEK) é um polímero amplamente estudado na obtenção de membranas para uso em células a combustíveis que utilizam membranas poliméricas, seja na forma pura ou misturado com outros componentes ${ }^{[12-15]}$.

Na última década, foi proposto que compostos heterocíclicos, como imidazol, pirazol e benzoimidazol ${ }^{[16-22]}$ poderiam melhorar as propriedades das membranas poliméricas, aumentando sua condutividade de prótons em baixas condições de umidade ${ }^{[23]}$.

Heteropoliácidos, como o ácido fosfotúngstico ${ }^{[24,25]}$, ácido molibdofosfórico ${ }^{[26]}$ e ácido silicotúngstico ${ }^{[27]}$ têm sido empregados na formulação de membranas compósitas, uma vez que esses compostos apresentam características de alta condutividade de prótons em baixas condições de umidade.

A estratégia considerada para este trabalho é similar àquela adotada por A. S. Gomes e colaboradores ${ }^{[28,29]}$, e consiste na obtenção de filmes poliméricos que produzidos a partir de SPEEK, modificados com derivados do benzoimidazol e que contenham ácido fosfotúngstico. Este trabalho teve como objetivo avaliar a estabilidade térmica dos filmes produzidos com SPEEK, derivados do benzoimidazol e ácido fosfotúngstico. Buscou-se estabelecer condições de temperatura para realização de ensaios de condutividade de prótons de tais filmes em ausência de água, tendo em vista sua aplicação como membranas em células a combustível que operam em temperatura próxima a $150{ }^{\circ} \mathrm{C}$.

\section{Experimental}

\section{Sulfonação do PEEK}

PEEK Victrex PF 450, gentilmente doado pela empresa Victrex USA, foi dissolvido em ácido sulfúrico (95-98\%) na temperatura ambiente e em atmosfera inerte ${ }^{[30]}$. Após a completa dissolução do polímero, a reação de sulfonação foi realizada na temperatura de $50{ }^{\circ} \mathrm{C}$, durante o tempo necessário para se obter o grau de sulfonação desejado. Depois de transcorrido o tempo de reação, o polímero sulfonado foi lentamente precipitado em água deionizada gelada e lavado com mais água deionizada durante o período necessário para que o pH da solução de lavagem se tornasse igual ao da água adicionada. A secagem do polímero sulfonado foi realizada na temperatura ambiente, sob vácuo.

Para determinação do grau de sulfonação (GS), definido como a razão do número de mols de SPEEK em relação ao número de mol total de unidades repetitivas de PEEK $^{[3] 1}$, e da capacidade de troca iônica (IEC), o SPEEK foi dissolvido em n-metilpirrolidona (NMP) e titulado com solução de hidróxido de sódio $(\mathrm{NaOH})$.

\section{Síntese dos derivados do benzoimidazol obtidos a partir de glicóis e de dibromo n-alcanos}

Esta síntese foi realizada em dois estágios, sendo que no primeiro estágio ${ }^{[32]}$ os precursores tetraetileno glicol (TEG) e poli(glicol etilênico) 400 (PEG 400) foram reagidos com tribrometo de fósforo $\left(\mathrm{PBr}_{3}\right)$. A reação foi realizada utilizando uma relação molar de 1:2,5 glicol/ $\mathrm{PBr}_{3}$ e diclorometano como solvente, na temperatura de $40{ }^{\circ} \mathrm{C}$, durante 48 horas. Após resfriamento até temperatura ambiente, água deionizada e gelo foram adicionados para terminar a reação, sendo posteriormente utilizado um funil de separação para separar a fase orgânica da fase aquosa. Após a obtenção da fase orgânica devidamente lavada (3 vezes no funil de separação), procedeu-se à retirada do solvente em um evaporador rotatório. Uma alíquota do composto foi separada para realização dos testes de caracterização espectroscópica e o restante foi destinado para utilização no segundo estágio.

No segundo estágio ${ }^{[33]}$, os derivados dibromados foram submetidos à reação com o benzoimidazol. A reação foi realizada utilizando-se de partida uma relação molar de 1:2,7:2,8 benzoimidazol/derivado dibromado/KOH e etanol como solvente, na temperatura a $80^{\circ} \mathrm{C}$, durante 3 horas. Após resfriamento até temperatura ambiente, realizou-se a filtragem do brometo de potássio $(\mathrm{KBr})$ formado durante a reação. O excesso de solvente (etanol) foi removido em um evaporador rotatório a $80{ }^{\circ} \mathrm{C}$. O resíduo orgânico foi então tratado com clorofórmio, sendo que o extrato de clorofórmio foi transferido para um funil de separação e lavado inicialmente em solução saturada de $\mathrm{NaOH}$ (3 vezes) e posteriormente em água deionizada (3 vezes). Após a lavagem, a solução foi seca com sulfato de sódio anidro e o solvente removido em um evaporador rotatório. O produto obtido na forma líquida teve uma alíquota separada para realização dos testes de caracterização espectroscópica, sendo o restante foi destinado à composição dos filmes poliméricos.

A síntese dos derivados de benzoimidazol a partir de dibrometos de alquila foi realizada de maneira análoga àquela utilizada na obtenção dos derivados de benzoimidazol descritos anteriormente ${ }^{[33]}$. O produto obtido na forma sólida foi recristalizado com acetonitrila a $60^{\circ} \mathrm{C}$ e seco a vácuo, sendo uma alíquota separada para caracterização espectroscópica e o restante destinado à composição dos filmes poliméricos.

\section{Formação dos filmes}

Os filmes foram formados a partir de uma solução de SPEEK, derivados do benzoimidazol e HPW, dissolvidos em n-metilpirrolidona (NMP). SPEEK de GS entre $50-70 \%$ foi utilizado, uma vez que membranas produzidas com GS abaixo desta faixa apresentam baixa condutividade de prótons e com GS acima desta faixa apresentam baixa estabilidade dimensional ${ }^{[34]}$.

A mistura entre os componentes foi realizada em duas etapas, pois resultados de trabalhos anteriores indicaram que essa seria a forma mais adequada de mistura ${ }^{[28,29]}$. Na primeira etapa foram misturados SPEEK e derivados do benzoimidazol, dissolvidos em NMP. Na segunda etapa, foi adicionada 
Tabela 1. Composição dos filmes produzidos.

\begin{tabular}{|c|c|c|c|c|c|c|}
\hline Membrana & $\mathbf{G S}^{\mathbf{a}}$ & $\mathbf{B Z I}^{\mathrm{b}}$ & $\mathrm{SO}_{3} / \mathrm{BZI}^{\mathrm{c}}$ & $\operatorname{SPEEK}^{\mathrm{d}}(\%)$ & $\mathbf{B Z I}^{\mathrm{e}}(\%)$ & $\mathrm{HPW}^{\mathrm{f}}(\%)$ \\
\hline 56 & 56 & - & - & 100 & - & - \\
\hline $56 \mathrm{D} 12$ & 56 & Dibrometo de decila & 12 & 97 & 3 & - \\
\hline $56 \mathrm{D} 12 \mathrm{H} 5$ & 56 & Dibrometo de decila & 12 & 93 & 2 & 5 \\
\hline $56 \mathrm{D} 12 \mathrm{H} 10$ & 56 & Dibrometo de decila & 12 & 88 & 2 & 10 \\
\hline $56 \mathrm{D} 12 \mathrm{H} 30$ & 56 & Dibrometo de decila & 12 & 68 & 2 & 30 \\
\hline 56TE12 & 56 & Tetraetileno glicol & 12 & 97 & 3 & - \\
\hline $56 \mathrm{TE} 12 \mathrm{H} 5$ & 56 & Tetraetileno glicol & 12 & 92 & 3 & 5 \\
\hline 56TE12H10 & 56 & Tetraetileno glicol & 12 & 88 & 2 & 10 \\
\hline 56TE12H30 & 56 & Tetraetileno glicol & 12 & 68 & 2 & 30 \\
\hline 65 & 65 & - & - & 100 & - & - \\
\hline $65 \mathrm{~B} 12$ & 65 & Dibrometo de butila & 12 & 98 & 2 & - \\
\hline $65 \mathrm{D} 6$ & 65 & Dibrometo de decila & 6 & 94 & 6 & - \\
\hline $65 \mathrm{D} 12$ & 65 & Dibrometo de decila & 12 & 97 & 3 & - \\
\hline 65D12H5 & 65 & Dibrometo de decila & 12 & 92 & 3 & 5 \\
\hline 65D12H10 & 65 & Dibrometo de decila & 12 & 87 & 3 & 30 \\
\hline $65 \mathrm{D} 12 \mathrm{H} 30$ & 65 & Dibrometo de decila & 12 & 68 & 2 & 30 \\
\hline 65TE12 & 65 & Tetraetileno glicol & 12 & 97 & 3 & - \\
\hline 65TE12H5 & 65 & Tetraetileno glicol & 12 & 92 & 3 & 5 \\
\hline $65 \mathrm{TE} 12 \mathrm{H} 10$ & 65 & Tetraetileno glicol & 12 & 87 & 3 & 10 \\
\hline 65TE12H30 & 65 & Tetraetileno glicol & 12 & 68 & 2 & 30 \\
\hline 65PE12 & 65 & Polietileno glicol & 12 & 95 & 5 & - \\
\hline $65 \mathrm{PE} 12 \mathrm{H} 10$ & 65 & Polietileno glicol & 12 & 86 & 4 & 10 \\
\hline
\end{tabular}

a) Grau de sulfonação do SPEEK; b) Precursor do derivado do benzoimidazol; c) Razão molar entre ácido sulfônico do SPEEK e derivado de benzoimidazol; d) percentual em massa de SPEEK presente na membrana; e) percentual em massa de derivado do benzoimidazol presente na membrana; e f) percentual de ácido fosfotúngstico presente na membrana.

a quantidade adequada de uma solução de HPW em NMP. A solução obtida da mistura entre SPEEK, derivados do benzoimidazol e HPW foi filtrada em filtros Millipore e vertida em placa de Petri, ficando em repouso numa estufa aberta, a $60{ }^{\circ} \mathrm{C}$, durante 48 horas, para que o solvente evaporasse lentamente. Após esse procedimento, a estufa foi fechada, sendo aplicado vácuo a fim de remover o solvente residual. Então, os filmes formados foram retirados das placas de Petri e submetidos aos testes para estudo e caracterização de suas propriedades. A Tabela 1 indica os filmes produzidos, com suas composições correspondentes.

A abreviação de denominação dos filmes produzidos denota o grau de sulfonação (GS) do SPEEK, o tipo de derivado do benzoimidazol e a quantidade de HPW utilizada. Assim, no caso do filme 56, somente SPEEK com GS 56 foi utilizado, e no caso do filme 56 TE12 H10, foi utilizado SPEEK com GS 56, derivado do benzoimidazol obtido a partir do tetraetileno glicol na razão molar 12:1 em relação ao ácido sulfônico e $10 \%$ em massa de HPW. A relação molar 12: entre os derivados do benzoimidazol e o acido sulfônico foi estabelecida de acordo com os resultados obtidos em trabalhos realizados anteriormente ${ }^{[28,29]}$.

\section{Análise temogravimétrica}

Os ensaios de termogravimetria foram realizados em equipamento TGA Q50 TA Instruments. Foram utilizadas aproximadamente $10 \mathrm{mg}$ de filme e, após 3 minutos a
$30{ }^{\circ} \mathrm{C}$, a temperatura foi aumentada até $1000{ }^{\circ} \mathrm{C}$ numa taxa de $20^{\circ} \mathrm{C} / \mathrm{min}$.

Os ensaios de termogravimetria assim conduzidos tiveram como objetivo a determinação da temperatura máxima de utilização dos filmes em ensaios de condutividade de prótons, pois se pretende avaliar a condutividade de prótons desses filmes em temperaturas relativamente elevadas (até $150{ }^{\circ} \mathrm{C}$ ), tendo em vista a utilização desses filmes como membranas em células a combustível que operam em baixas condições de umidade e temperatura relativamente alta. Além disso, buscou-se avaliar a influência dos diversos componentes dos filmes na sua estabilidade térmica.

\section{Resultados e Discussão}

A composição dos filmes ocasiona as diferenças no seu comportamento de degradação térmica. O grau de sulfonação do SPEEK, o tipo de derivado do benzoimidazol e a quantidade de HPW são as variáveis na composição dos filmes que foram estudados neste trabalho.

\section{Sulfonação do PEEK e o solvente utilizado na formação dos filmes}

O grau de sulfonação (GS) é uma indicação da quantidade de grupos ácidos presentes no filme, de forma que um 
aumento em sua quantidade propicia um aumento na quantidade de água, pois esses grupos ácidos são hidrofílicos.

A reação de sulfonação, que origina o polímero sulfonado e hidrofílico, promove uma grande redução na estabilidade térmica do SPEEK em relação ao PEEK. Enquanto o PEEK apresenta perda de massa a partir de $550{ }^{\circ} \mathrm{C}$, o SPEEK apresenta perda de massa significativa a partir de $250{ }^{\circ} \mathrm{C}$ e os filmes produzidos com SPEEK apresentam perda de massa a partir de $100{ }^{\circ} \mathrm{C}$, conforme mostra a Figura 1a.

O SPEEK pode apresentar duas ou três regiões de perda de massa, devido à inserção de grupos sulfônicos $\left(\mathrm{SO}_{3}\right)$. Duas regiões aparecem quando SPEEK está completamente $\operatorname{seco}^{[35,36]}$ e três regiões quando há presença de umidade ${ }^{[37-38,39]}$. No caso dos filmes avaliados neste trabalho, na primeira região de perda de massa, até $150{ }^{\circ} \mathrm{C}$ ocorre a evaporação da umidade que foi absorvida do ar pelo SPEEK durante o manuseio da amostra. Na segunda região, entre 250 e $400{ }^{\circ} \mathrm{C}$

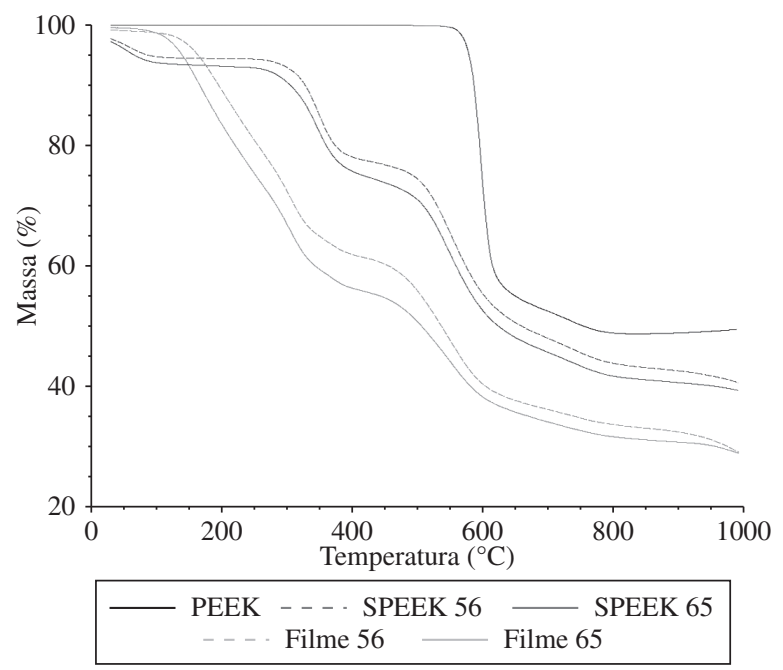

(a)

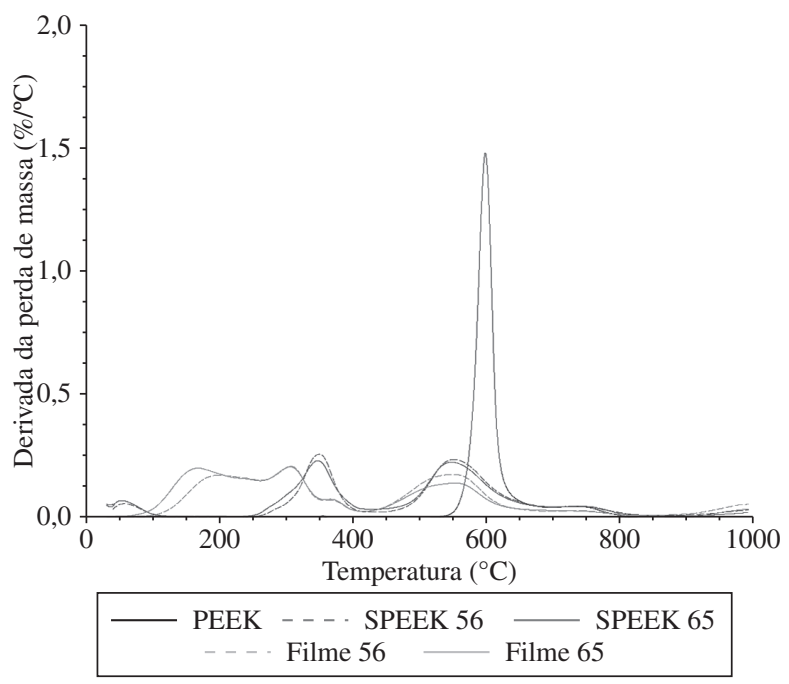

(b)

Figura 1. PEEK, SPEEK de graus de sulfonação 56 e 65 e filmes de SPEEK de graus de sulfonação 56 e 65: a) Perda de massa em função da temperatura; e b) Derivada da perda de massa em função da temperatura. ocorre a degradação do grupo ácido sulfônico. Na terceira região, desde 550 até $800{ }^{\circ} \mathrm{C}$ ocorre degradação da cadeia polimérica, como mostra a Figura $1 \mathrm{~b}$.

A utilização de n-metilpirrolidona (NMP) como solvente de SPEEK na formação dos filmes modifica o perfil de degradação térmica dos filmes produzidos em relação ao SPEEK, como mostra a Figura 1b. Nos filmes, o pico referente à degradação do $\mathrm{SO}_{3}$ é deslocado para temperaturas inferiores àquelas do SPEEK. Além disso, os filmes apresentam ainda um pico de degradação à temperatura inferior àquela do $\mathrm{SO}_{3}$, que ocorre devido à presença do solvente. Esse comportamento indica que a NMP não é completamente removida dos filmes com o procedimento de secagem a vácuo na temperatura de $60{ }^{\circ} \mathrm{C}$. A necessidade da temperatura superior a $60{ }^{\circ} \mathrm{C}$ para retirada de NMP no processo de secagem foi reportada por Robertson e colaboradores ${ }^{[40]}$. A retenção do solvente é considerada responsável pela redução da condutividade de prótons em membranas de SPEEK $^{[41]}$. Dessa forma, antes da realização de testes de condutividade, os filmes poliméricos devem ser submetidos a um processo de secagem, sendo indicada a temperatura de $130{ }^{\circ} \mathrm{C}$ durante, pelo menos, 24 horas ${ }^{[40]}$, ou ainda $100{ }^{\circ} \mathrm{C}$ durante 2 semanas ${ }^{[14]}$.

Em recente trabalho, Krishnan e colaboradores ${ }^{[34]}$ prepararam e caracterizaram membranas compósitas, produzidas com SPEEK com GS 65 e ácido fosfoantimônico, utilizando dimetil formamida como solvente. As membranas apresentam a decomposição do ácido sulfônico em temperaturas $10-20{ }^{\circ} \mathrm{C}$ inferiores em relação às temperaturas obtidas para membranas preparadas somente com SPEEK. A decomposição da cadeia polimérica segue o mesmo padrão, com temperaturas 20-30 ${ }^{\circ} \mathrm{C}$ menores nas membranas compósitas. Não foi realizada nenhuma inferência sobre o solvente utilizado e a modificação no perfil de degradação térmica das membranas.

\section{Umidade dos filmes e sua influência na estabilidade térmica}

Através de avaliações preliminares foi verificado que em 48 horas expostos ao ambiente os filmes poliméricos atingem o máximo de absorção de umidade. Assim, com objetivo de comparar a estabilidade térmica dos filmes secos e úmidos, foram utilizados filmes secos a vácuo na temperatura ambiente durante 48 horas e filmes condicionados 48 horas na umidade ambiente.

O aumento no grau de sulfonação diminui a temperatura de degradação dos filmes secos, conforme mostra a Figura 2a. Na faixa inicial de degradação, em temperaturas entre 150 e $200{ }^{\circ} \mathrm{C}$, o filme 56 apresenta o primeiro pico de perda de massa aproximadamente a $200{ }^{\circ} \mathrm{C}$ e o filme 65 apresenta o primeiro pico aproximadamente a $170{ }^{\circ} \mathrm{C}$. Esse comportamento é indicado Figura $2 b$, que mostra as curvas da derivada da perda de massa em função da temperatura dos filmes produzidos com SPEEK de graus de sulfonação 56 e 65 , secos e úmidos.

Nos filmes expostos ao ambiente verifica-se a presença de umidade, liberada na faixa entre $80-90{ }^{\circ} \mathrm{C}$. Comparando-se o 


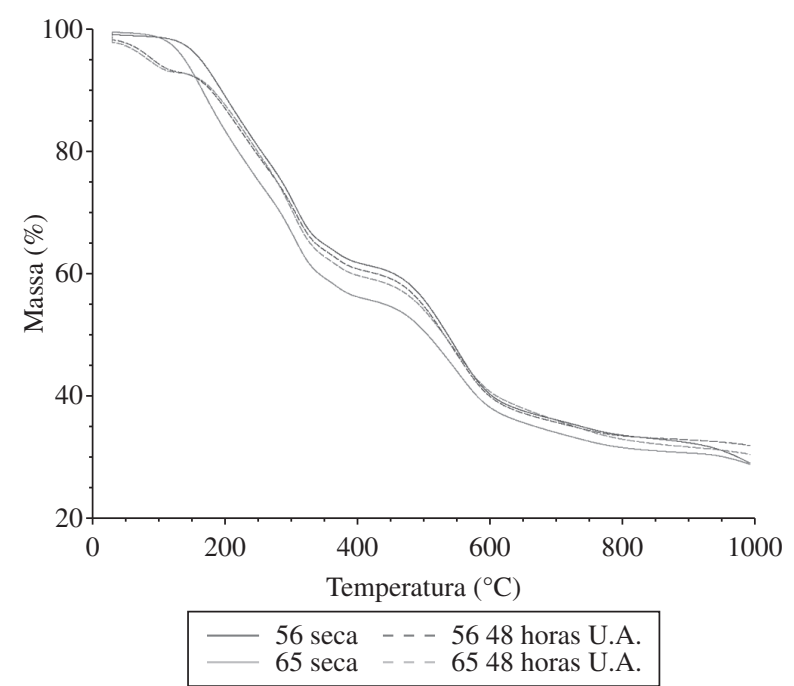

(a)

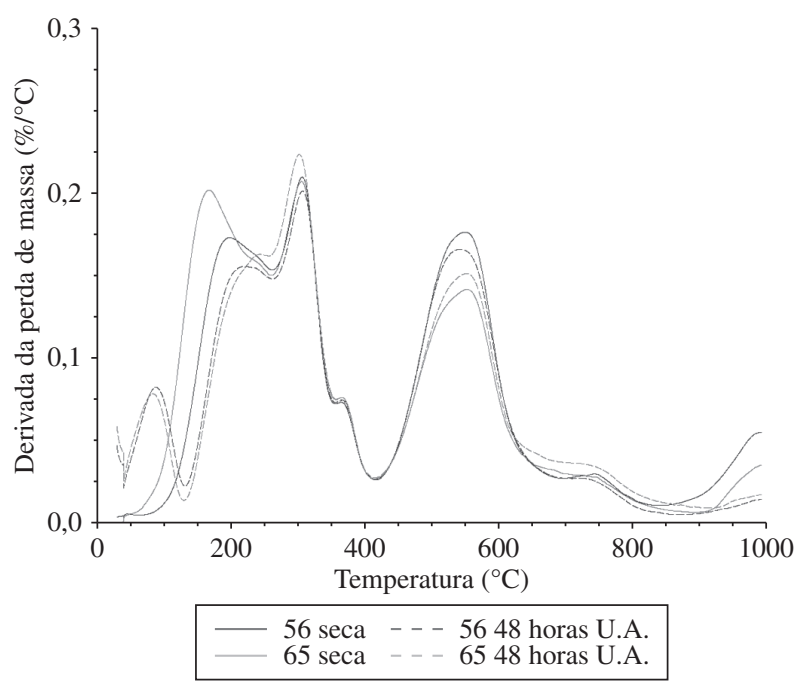

(b)

Figura 2. Filmes de SPEEK de graus de sulfonação 56 e 65, secos e úmidos: a) Perda de massa em função da temperatura; e b) Derivada da perda de massa em função da temperatura.

perfil de degradação do primeiro pico de perda de massa dos filmes secos e úmidos, nota-se que nos filmes úmidos ocorre um deslocamento desse pico para temperaturas mais elevadas. Esse comportamento indica uma interação entre a umidade do ambiente que foi absorvida pelos filmes e o solvente utilizado $^{[40,41]}$. Essa interação é mais intensa no filme de maior grau de sulfonação (65), conforme mostra a Figura 2b.

\section{Derivados do benzoimidazol e sua influência nas propriedades térmicas dos filmes}

Os derivados do benzoimidazol utilizados neste trabalho diferem em relação a seus precursores. Derivados obtidos a partir de dibrometos de alquila apresentam somente carbono e hidrogênio na cadeia principal, enquanto que os derivados de óxidos de etileno (glicóis) apresentam átomos de oxigênio na cadeia principal. Essa diferença na estrutura dos precurso- res faz com que os derivados do benzoimidazol e, conseqüentemente, as membranas obtidas a partir destes, apresentem propriedades distintas.

Os filmes produzidos apresentam estabilidade térmica inferior àquela do SPEEK do qual são originados. Entretanto, a utilização de derivados do benzoimidazol na composição dos filmes aumenta sua estabilidade térmica em relação aos filmes contendo somente SPEEK, conforme indica a Figura 3a, que mostra filmes de SPEEK com GS 65.

Diversos trabalhos ${ }^{[42-47]}$ relatam que imidazol e benzoimidazol, quando adequadamente utilizados, aumentam a estabilidade térmica de membranas produzidas. Os derivados do benzoimidazol utilizados neste trabalho influenciam o perfil de degradação dos filmes na faixa de degradação do ácido sulfônico, na região de mais baixa temperatura, que é afetada pela presença do solvente ${ }^{[40,41]}$. Esse comportamento indica que ocorre interação entre os derivados do benzoimidazol

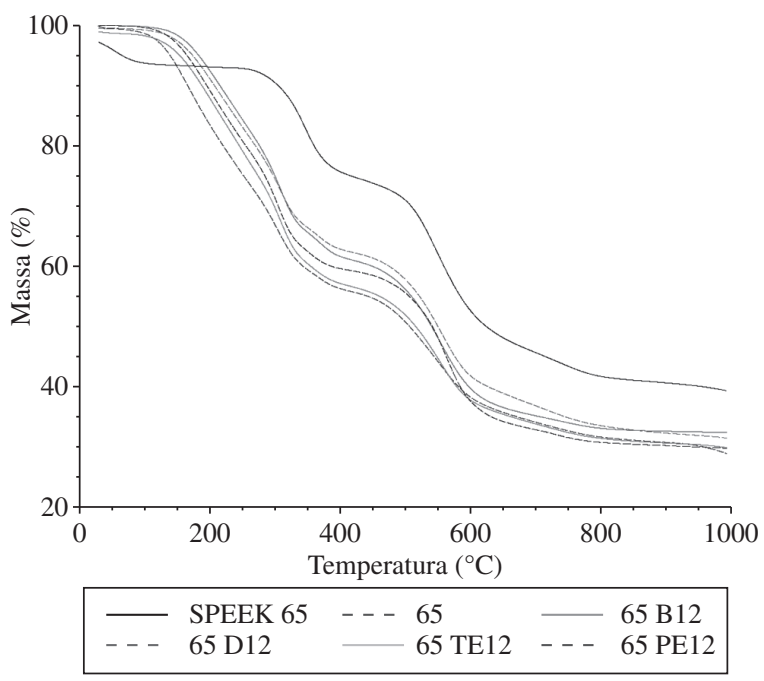

(a)

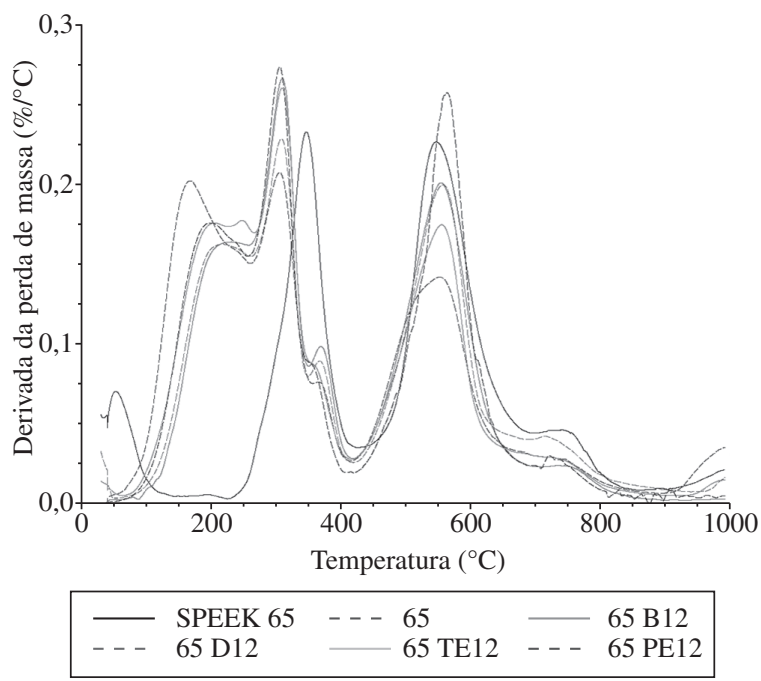

(b)

Figura 3. Filmes de SPEEK de GS 65 contendo diversos derivados do benzoimidazol: a) Perda de massa em função da temperatura; e b) Derivada da perda de massa em função da temperatura. 
e o solvente utilizado, como pode ser notado pela diferença das curvas da derivada da perda de massa, na faixa entre $150-250{ }^{\circ} \mathrm{C}$, da Figura $2 \mathrm{~b}$.

Os derivados do benzoimidazol obtidos a partir dos dibrometos de alquila deslocam o primeiro pico da derivada da perda de massa para temperaturas maiores que os óxidos de etileno (glicóis), conforme mostra a Figura 3b. A presença de oxigênio na cadeia principal dos derivados do benzoimidazol obtidos a partir de glicóis faz com que o referido pico de perda de massa seja deslocado a uma temperatura inferior àquela apresentada pelos derivados obtidos a partir de dibrometos de alquila. Isso ocorre porque os oxigênios na cadeia principal dos derivados obtidos a partir dos glicóis proporcionam uma maior afinidade com o solvente, fazendo com que a interação com o solvente seja mais pronunciada.

O deslocamento da temperatura de degradação na faixa de temperatura de degradação do ácido sulfônico está relacionado somente à estrutura química do precursor do derivado do benzoimidazol, pois a massa molar dos compostos utilizados não apresenta influência significativa na faixa de temperatura onde ocorre cada uma das perdas de massa, como mostrado na Figura 2b. Nas demais temperaturas de degradação não foram verificadas variações significativas relacionadas à utilização de derivados do benzoimidazol.

\section{Influência do ácido fosfotúngstico nas propriedades térmicas dos filmes}

A utilização de ácido fosfotúngstico (HPW) na composição do filme influencia o padrão de degradação térmica. A adição de $30 \%$ em massa de HPW diminui a perda de massa do filme entre 500 e $900{ }^{\circ} \mathrm{C}$, conforme indica a Figura 4a. O HPW puro apresenta apenas região de perda de massa, ao redor dos $150^{\circ} \mathrm{C}$, devido à desidratação da água de cristalização ${ }^{[48,49]}$.

Entretanto, a adição de HPW diminui a temperatura onde a velocidade de perda de massa é máxima, na faixa temperatura de degradação da matriz polimérica. Esse comportamento é evidenciado na Figura 4b, onde se nota que os filmes produzidos com HPW apresentam o pico de velocidade de perda de massa máxima próximo a $400{ }^{\circ} \mathrm{C}$, enquanto o filme sem HPW e o SPEEK apresenta o referido pico próximo a $600{ }^{\circ} \mathrm{C}$. Os filmes que contêm SPEEK de GS 65 e $30 \%$ de HPW apresentam também um pronunciado aumento na velocidade de degradação na região do ácido sulfônico, independente do derivado de benzoimidazol utilizado em sua composição, conforme mostra a Figura 4b.

Variando a quantidade de HPW adicionada nos filmes, verificou-se que o aumento da quantidade de HPW nos filmes diminui temperatura de degradação na faixa da matriz polimérica. Esse comportamento foi apresentado por todos os filmes que contêm HPW em sua composição, independente do derivado do benzoimidazol e do grau de sulfonação utilizados, conforme indicam as Figuras de 5 a 8 . O mesmo padrão de comportamento é relatado quando adicionado HPW tanto em membranas produzidas com poli (ftalazinona éter cetona) ${ }^{[49]}$,

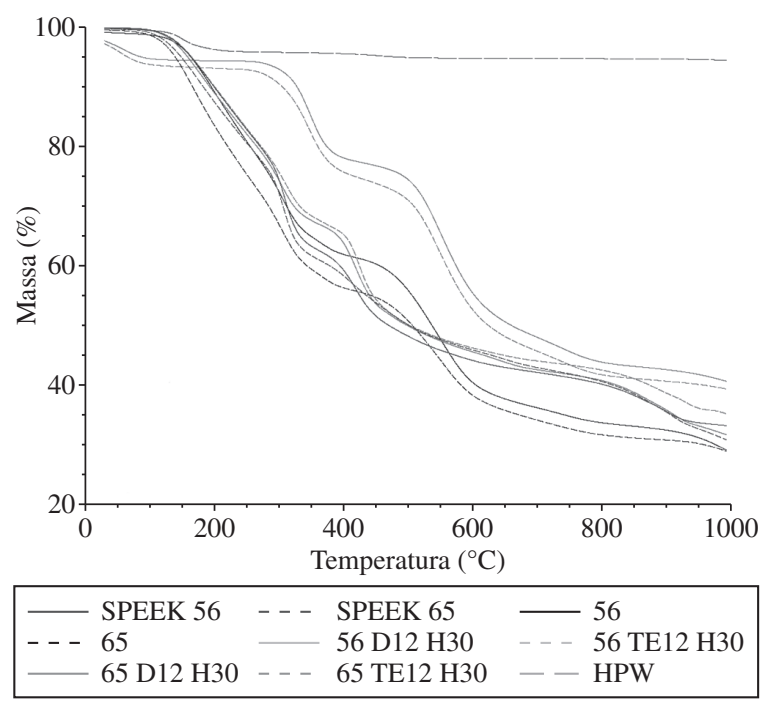

(a)

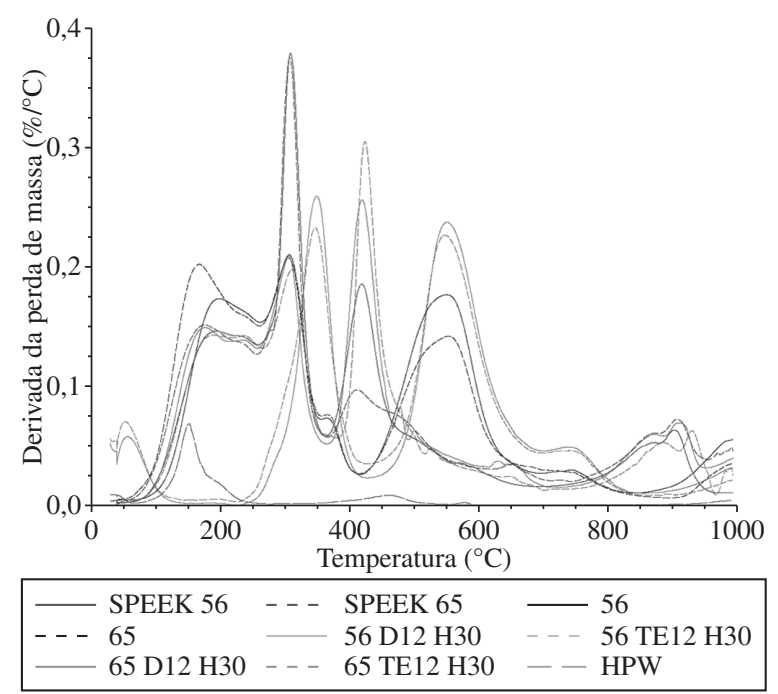

(b)

Figura 4. Filmes de SPEEK de GS 56 e 65 contendo derivados do benzoimidazol e 30\% em massa de HPW: a) Perda de massa em função da temperatura; e b) derivada da perda de massa em função da temperatura.

como em membranas produzidas com silicone contendo nanopartículas de poliacrilato ${ }^{[48]}$ e em membranas produzidas com poli(imida) sulfonada ${ }^{[50]}$. Adicionando outro heteropoliácido ao SPEEK, como o fosfato de zircônia sulfofenileno fosfatado, ocorre aumento da estabilidade térmica quando a quantidade de HPW utilizada é de até $30 \%$ em massa, sendo que acima dessa quantidade a estabilidade térmica diminui ${ }^{[34]}$.

A temperatura onde a velocidade de perda de massa é máxima corresponde a $550{ }^{\circ} \mathrm{C}$ nos filmes produzidos somente com SPEEK, independente do GS utilizado. Quando adicionado $5 \%$ de HPW, a temperatura diminui para a faixa dos $500-510{ }^{\circ} \mathrm{C}$. Adicionando de $10 \%$ de HPW, a temperatura fica na faixa dos $465-495{ }^{\circ} \mathrm{C}$ e adicionando $30 \%$ de HPW a temperatura fica na faixa dos $410-425^{\circ} \mathrm{C}$.

$\mathrm{Na}$ faixa de degradação da matriz polimérica, os filmes produzidos com GS 56, mesmos percentuais de HPW e di- 


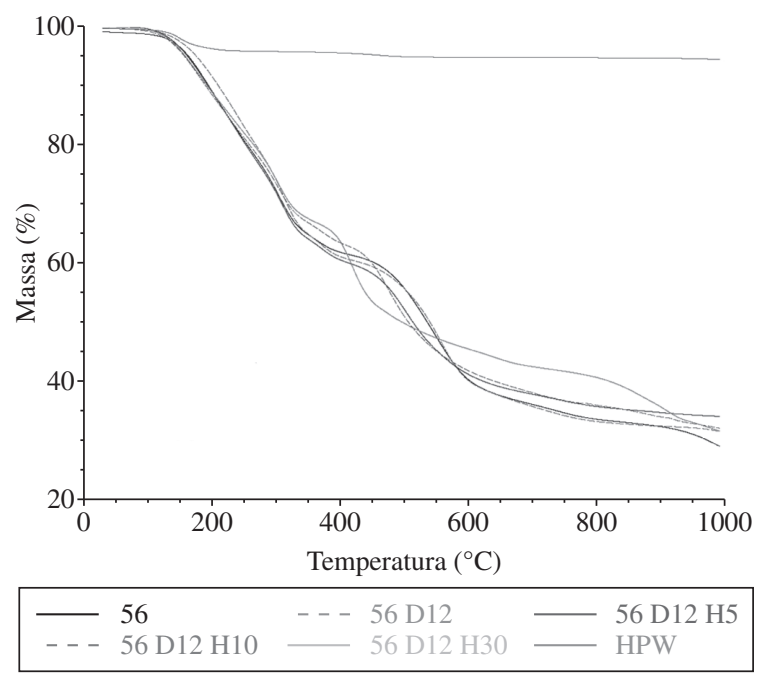

(a)

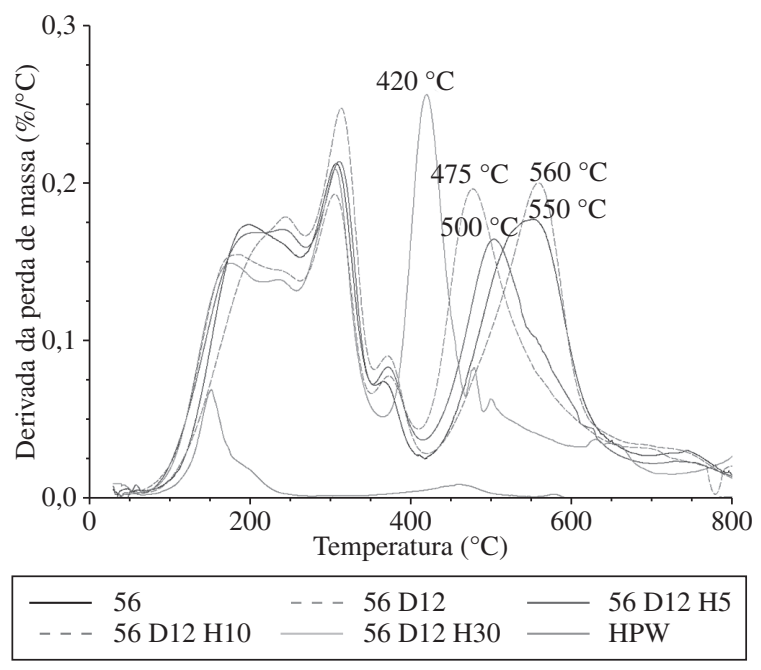

(b)

Figura 5. Filmes de SPEEK de GS 56 contendo derivados do benzoimidazol obtidos a partir do dibrometo de decila, com diversos percentuais de HPW: a) Perda de massa em função da temperatura; e b) Derivada da perda de massa em função da temperatura.

ferentes derivados do benzoimidazol apresentam comportamento semelhante, com a temperatura onde a perda de massa é máxima diminuindo e a velocidade de degradação aumentando, conforme mostram as Figuras 5 b e 6 b.

Para a mesma faixa de degradação, os filmes produzidos com GS 65, mesmos percentuais de HPW e diferentes derivados do benzoimidazol, o comportamento de degradação é semelhante, com ambas temperatura e velocidade onde a perda de massa é máxima diminuindo, conforme mostram as Figuras $7 b$ e $8 b$.

A adição de HPW nos filmes foi realizada devido à possibilidade de aumentar sua condutividade de prótons quando usados como membranas em células a combustível ${ }^{[28,29]}$. Entretanto, os resultados obtidos neste trabalho indicam que o aumento na quantidade de HPW compromete a estabilidade térmica da matriz polimérica, de modo que a vida útil da

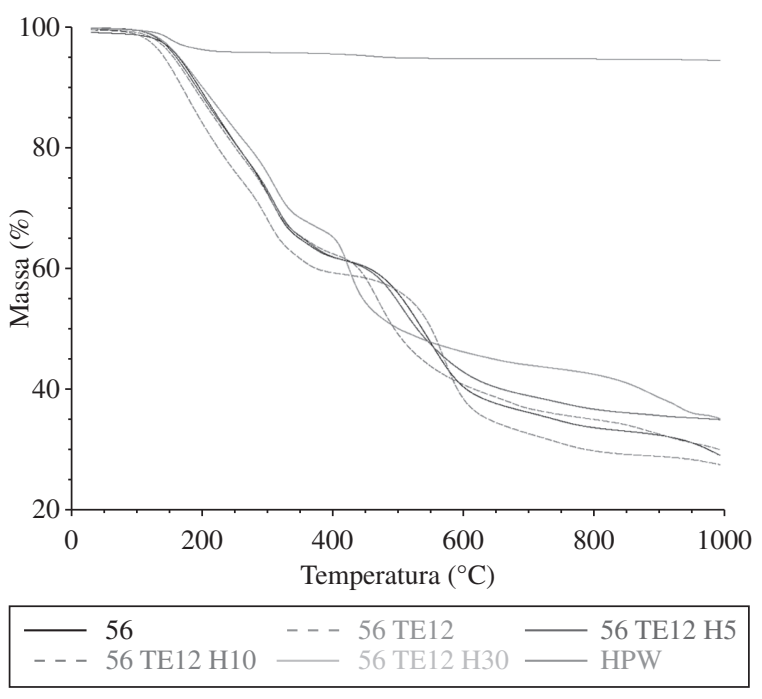

(a)

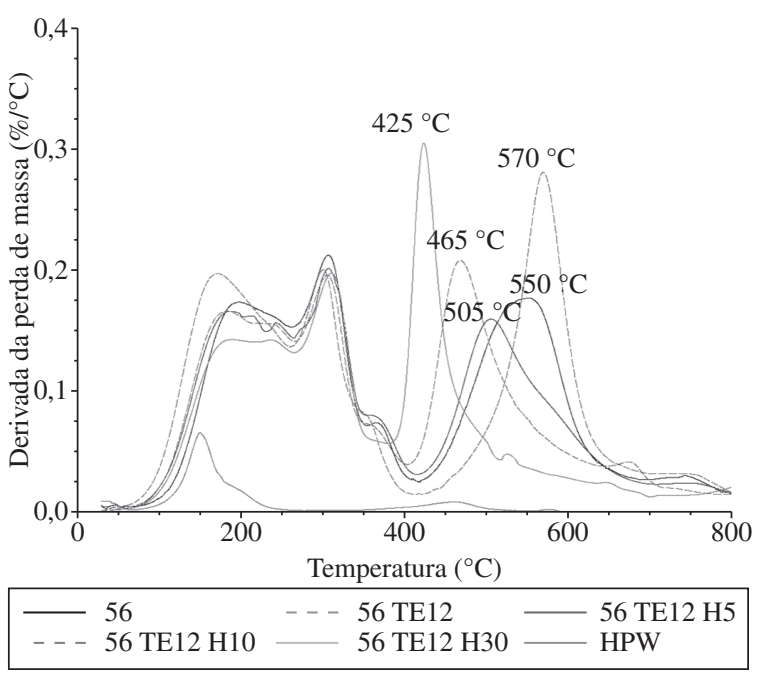

(b)

Figura 6. Filmes de SPEEK de GS 56 contendo derivados do benzoimidazol obtidos a partir do tetraetileno glicol, com diversos percentuais de HPW: a) Perda de massa em função da temperatura; e b) Derivada da perda de massa em função da temperatura.

membrana pode ficar comprometida. Em trabalhos futuros pretende-se verificar a influência da quantidade de HPW na condutividade de prótons dos filmes, buscando a definição da quantidade que apresenta melhor compromisso entre condutividade e durabilidade.

\section{Conclusões}

As propriedades térmicas dos filmes compostos de poli(éter éter cetona) sulfonado, derivados do benzoimidazol e ácido fosfotúngstico dependem da sua composição.

A reação de sulfonação diminui a estabilidade térmica do SPEEK em relação ao PEEK. A utilização de n-metilpirrolidona (NMP) como solvente de SPEEK modifica o perfil de degradação térmica dos filmes produzidos, sendo necessária 


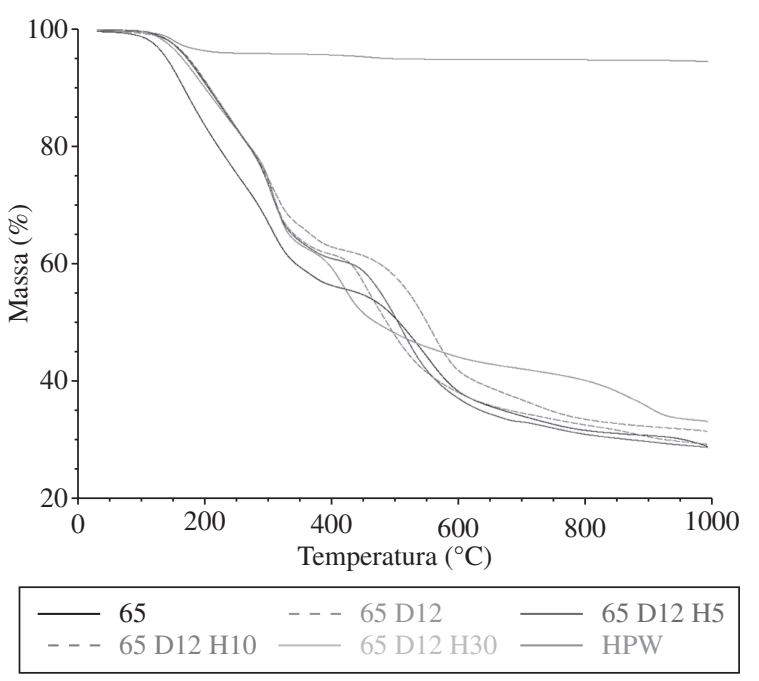

(a)

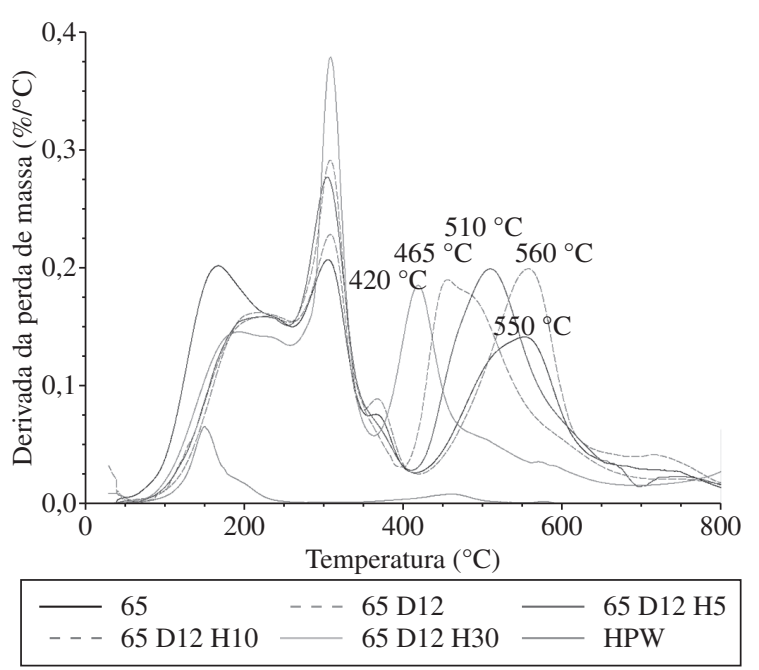

(b)

Figura 7. Filmes de SPEEK de GS 65 contendo derivados do benzoimidazol obtidos a partir do dibrometo de decila, com diversos percentuais de HPW: a) Perda de massa em função da temperatura; e b) Derivada da perda de massa em função da temperatura.

a total remoção desse solvente antes de se proceder com os ensaios de condutividade de prótons.

Filmes produzidos com derivados do benzoimidazol obtidos a partir de glicóis apresentam perda de massa em temperaturas inferiores a aquelas produzidas com derivados do benzoimidazol obtidos a partir de dibrometos de alquila.

A utilização de ácido fosfotúngstico diminui a temperatura de degradação, de modo que quanto maior a quantidade de ácido fosfotúngstico adicionada, menor será sua temperatura de degradação.

Para formação de uma membrana com possibilidade de condutividade de prótons e estabilidade térmica elevadas, a composição sugerida como a mais adequada compreende a utilização de SPEEK com grau de sulfonação entre 55 e 60 , utilizando o derivado do benzoimidazol obtido a partir do di-

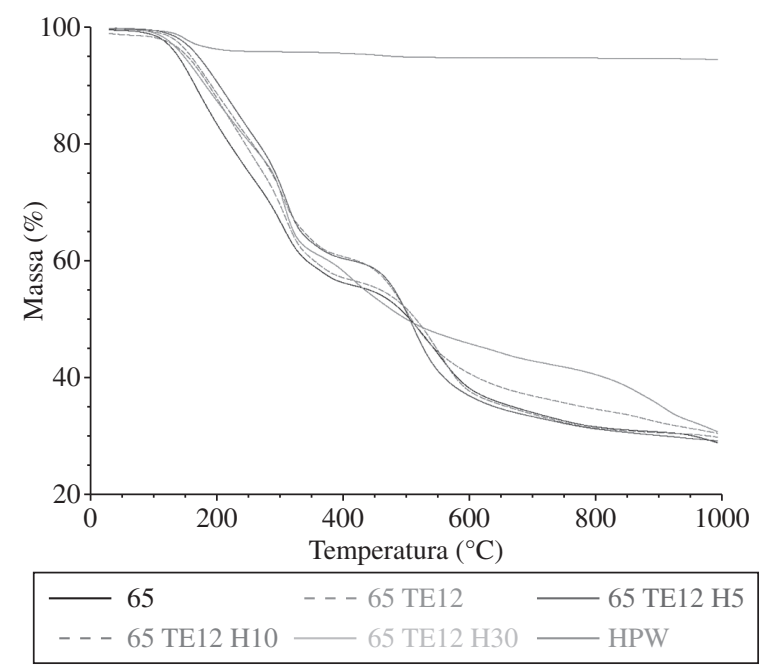

(a)

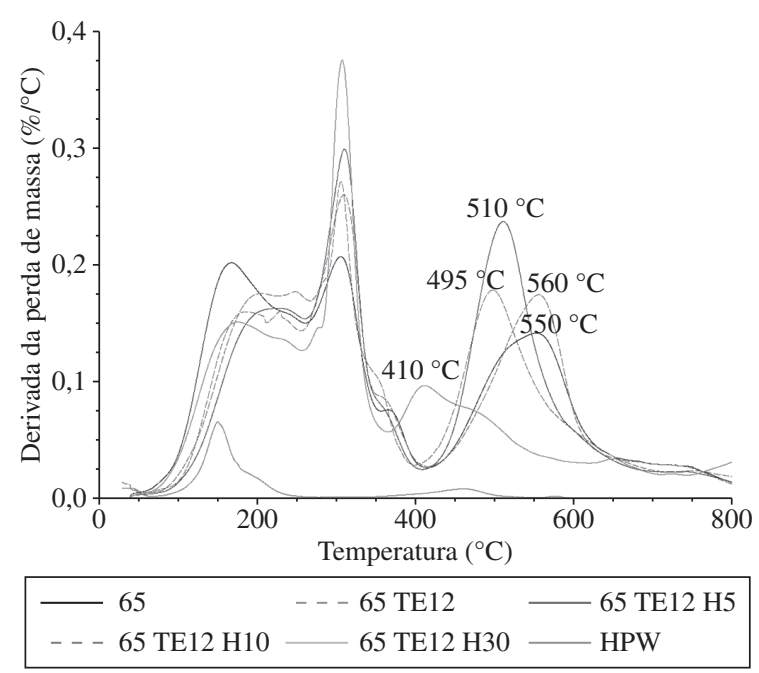

(b)

Figura 8. Filmes de SPEEK de GS 65 contendo derivados do benzoimidazol obtidos a partir do tetraetileno glicol, com diversos percentuais de HPW: a) Perda de massa em função da temperatura; e b) Derivada da perda de massa em função da temperatura.

brometo de decila na razão molar 12:1 em relação ao ácido sulfônico e até $10 \%$ em massa de HPW.

\section{Agradecimentos}

Os autores agradecem CAPES, CNPQ e PRONEX/FAP ERGS pelo auxílio financeiro concedido e as empresas Lati Thermoplastics Italy, Victrex USA e Ensinger Brasil pelo fornecimento das amostras de PEEK.

\section{Referências Bibliográficas}

1. Mano, E. B.; Pacheco, E. B. A. V. \& Bonelli, C. M. C. - "Meio ambiente, poluição e reciclagem”, Blücher, São Paulo (2005). 
2. Hirshenhofer, J. H.; Stauffer, D. B. \& Engleman, R. R. "Fuel Cells: A Handbook" Gilbert/Commonwealth, Inc, BUSINESS/TECHNOLOGY BOOKS (1996).

3. Cook, B. - "An Introduction to Fuel Cells and Hydrogen Technology", Heliocentris, 3652 West $5^{\text {th }}$ Avenue, Vancouver, BC V6R-1S2, Canada, December 2001.

4. Rogers, G. - Fuel Cell Technology Handbook, CRC Press LLC, 2003 (ISBN 0-8493-0877-1).

5. Larmine, J. \& Dicks, A. - Fuel Cell Systems Explained $\left(2^{\circ}\right.$ Edition), Wiley, 2003.

6. Smitha, B.; Sridhar S. \& Khan, A. A. J. - Membr. Sci. 259, p.10 (2005).

7. Liang, Z. X.; Zhao, T. S.; Xu, C. \& Xu, J. B. - Electrochim. Acta 53, p.894 (2007).

8. Jung, H-J. \& Park, J-K. - Electrochim. Acta 52, p.7464 (2007).

9. Heo, K.-B.; Lee, H.-J.; Kim, H.-J.; Kim, B.-S.; Lee, S. Y.; Cho, E.; Oh, I.-H.; Hong, S.-A. \& Lim, T. H. J. - Power Sources 172, p.215 (2007).

10. Arnett, N. Y.; Harrison, W. L.; Badami, A. S.; Roy, A.; Lane, O.; Cromer, F.; Dong, L. \& McGrath, J. E. J. - Power Sources 172, p.20 (2007).

11. Lee, C. H.; Min, K. A.; Park, H. B.; Hong, Y. T.; Jung, B. O. \& Lee, Y. M. J. - Membr. Sci. 303, p.258 (2007)

12. Mikhailenko, S. D.; Wang, K.; Kaliaguine, S.; Xing, P.; Robertson, G. P. \& Guiver, M. D. J. - Membr. Sci. 223, p.93 (2004).

13. Sambandam, S. \& Ramani, V. J. - Power Sources 170, p.259 (2007).

14. Jaafar, J.; Ismail, A. F. \& Mustafa, A. - Mat. Sci. Engineer. A 460-461, p.475 (2007).

15. Othman, M. H. D.; Ismail, A. F. \& Mustafa, A. J. - Membr. Sci 299, p.156 (2007).

16. Kreuer, K. D. - Solid State Ionics 97, p.1 (1997).

17. Kreuer, K. D. A.; Fuchs, M.; Ise, M. \& Spaeth, J. - Maier. Electrochim. Acta 43, p.1281 (1998)

18. Kreuer, K. D. - Solid State Ionics 136-137, p.149 (2000).

19. Kreuer, K. D. J. - Membr. Sci. 185, p.29 (2000).

20. Schuster, M; Meyer, W. H.; Wegner, G.; Herz, H. G.; Ise, M.; Schuster, M.; Kreuer, K. D. \& Maier, J. - Solid State Ionics 145, p.85 (2001).

21. Münch, W.; Kreuer, K. D.; Silvestri, W.; Maier, J. \& Seifert G. - Solid State Ionics 145, p.437 (2001).

22. Herz, H. G.; Kreuer, K. D.; Maier, J.; Scharfenberger, G.; Schuster, M. F. H. \& Meyer, W. H. - Electrochim. Acta 48, p.2165 (2003).

23. Yamada, M. \& Honma I. - Electrochim. Acta 48, p.2411 (2003).

24. Kim, H-J.; Shul, Y-G. \& Han, H. J. - Power Sources 158, p.137 (2006).

25. Ramani, V.; Kunz, H. R. \& Fenton, J. M. J. - Membr. Sci. 279. p.506 (2006).

26. Ahmad, M. I.; Zaidi, S. M. J. \& Rahman, S. U. - Desalin. 193 , p.387 (2006).
27. Helen, M.; Viswanathan, B. \& Murthy, S. S. J. - Power Sources 163, p.433 (2006).

28. Carvalho, L. M.; Tan, A. R. \& Gomes, A. S. - Proceedings of International Hydrogen Energy Congress and Exhibition IHEC, Istanbul, 2005

29. Tan, A. R.; Carvalho, L. M. \& Gomes, A. S. - Macrom. Symp. 229, p.168 (2005).

30. Chang J-H.; Park, J. H.; Park, G-G.; Kim, C-S. \& Park, O. O. J. - Power Sources. 124, p.18 (2003).

31. Jiang, R.; Kunz, H. R. \& Fenton, J. M. J. Power Sources 150, p.120 (2000).

32. Botteghi, C.; Delogu, G.; Marchetti, M.; Paganelli, S. \& Sechi, B. J. - Mol. Catalys. A: Chemical 143, p.311 (1999).

33. Küçükbay, H.; Durmaz, R.; Orhan, E. \& Günal, S. - Il Farmaco 58, p.431 (2004).

34. Krishnan, P.; Park, J-S.; Yang, T-H.; Lee, W-Y. \& Kim, C-S. J. - Power Sources 163, p.2 (2006).

35. Zhong, S.; Cui, X.; Cai, H.; Fu, T.; Zhao, C. \& Na, H. J. - Power Sources 164, p.65 (2007).

36. Zhong, S. Cui, X., Cai, H., Fu, T., Shao, K. e Na, H. J. Power Sources 168, p.154 (2007).

37. Carbone, A.; Pedicini, R.; Portale, G.; Longo, A.; D’Ilariio, L. \& Passalacqua, E. J. - Power Sources 163, p.18 (2006).

38. Chen, J.; Maekawa, Y.; Asano, M. \& Yoshida, M. - Polymer 48, p.6002 (2007).

39. Krishnan, P.; Park, J-S. \& Kim, C-S. - Eur. Polym. J. 43, p.4019 (2007)

40. Robertson, G. P.; Mikhailenko, S. D.; Wang, K.; Xing, P.; Guiver, M. \& Kaliaguine, S. J. - Membr. Sci. 219, p.113 (2003).

41. Kaliaguine, S.; Mikhailenko, S. D.; Wang, K. P.; Xing, P.; Robertson, G. \& Guiver, M. - Catalysis Today 82, p.213 (2003).

42. Kufaci, M.; Bozkurt, A. \& Tülü, M. - Solid State Ionics 177, p.1003 (2006).

43. Persson, J. C.; Josefsson, K. \& Jannash, P. - Polymer 47, p.991 (2006).

44. Li, S.; Zhou, Z.; Liu, M.; Li, Wen; Ukai, J.; Hase, K. \& Nakanishi, M. - Electrochim. Acta, 51, p.1351 (2006).

45. Liu, Y. F., Yu, Q. C. Jun, Y., Liang, M. e Wu, Y. H. - Eur. Polym. J. 42, p. 2199 (2006).

46. Liu, Y. F.; Yu, Q. C. \& Wu, Y. H. J. - Phys. Chem. Sol. 68, p.201 (2007)

47. Liu, Y. F.; Yu, Q. C. \& Wu, Y. H. - Electrochim. Acta 52, p.8133 (2007).

48. Cui, X.; Zhong, S. \& Wang, H. J. - Power Sources 173, p.28 (2007).

49. Zhang, H.; Zhu, B. \& Xu, Y. - Solid State Ionics 177, p.1123 (2006).

50. Jang, W.; Choi, S.; Lee, S.; Shul, Y. \& Han, H. - Polym. Degrad. Stab. 92, p.1289 (2007).

Enviado: $14 / 08 / 07$

Reenviado: $10 / 12 / 07$

Aceito: $20 / 12 / 07$ 